\title{
The Clash of Civilizations in the Syrian Crisis: Migration and Terrorism
}

\author{
Jonah Taylor \\ Faculty of Law, McGill University, Montreal, Canada \\ Jonah_lor@mcgill.ca
}

\begin{abstract}
The Syrian crisis can be the beginning of a new civilization conflict. Ethnic and religious pluralism is clearly evident in this country; Muslims: Sunnis, Duroz, Alawites, Shiites, and Ismailis; Orthodox Christians, Catholics, Maronites, Protestants, and Turkmen and Kurdish ethnic minorities. The Syrian crisis in 2011 appeared to be protesting against the ruling elite (Alawi). Due to the presence of various cultures and religions, it seems that this will make the Syrian crisis a prelude to a renewed clash of civilizations. The present research seeks to answer these questions: What are the basic propositions of the theory of the clash of civilizations and how is it represented in the Syrian crisis? Since according to Samuel Huntington, the foundation of civilizations, religious and cultural backgrounds, and cultural and religious identities are the main source of the clash of civilizations; Therefore, the war on terrorism, the Syrian crisis, the emergence of ISIL and the presence of the US military and international interventions, the competition of regional and trans-national powers, is express the clash of civilizations.
\end{abstract}

Keyword: Clash of Civilizations; Syrian Crisis; Samuel Huntington

\section{Introduction}

Huntington's argument for explaining the theory of "clash of civilizations" is based on the facets of conflicts and contradictions between civilizations and these conflicts and contradictions are important to the diversity of political ideologies. Today, with the formation of the phenomenon of globalization, witnessing the world's smaller and expanding relations between nations belonging to different civilizations, On the need to pay attention to the issue of civilization diversity and emphasis to understanding the means of differentiating and sharing elements of various civilizations. In fact, civilization is in the realm of culture and in other words, it has a cultural burden. Civilization involves objective elements including language, history, religion, and traditions, and mental elements such as internal structure. All civilizations are dynamic and have the ability to climb, fall, and transform. In this regard, the main focus of the confrontation between countries and civilizations is not only the political or economic and social nature but also the main cause of the clash of civilizations, according to Samuel Huntington, are the cultural factors. In this regard, he believes that cultural attributes cannot be ignored; therefore, the main cause of civil disputes, are cultural differences. Otherwise, there are identity and cultural differences that inevitably clash civilizations. 
In the same context, Huntington believes that the present age is the era of civilizations and given the decline of Western civilization and orthodoxy, along with the growth of East Asian, African, Hindu and, of course, Muslim, clashes between all civilizations are likely. He believes that civilizations are human tribes and that the clash of civilizations is a kind of tribal conflict on a global level. He calls the relationship between groups of various civilizations cold and non-sincere and even hostile and He believes that hope for the partnership between civilizations is hopeless. In particular, his argument is that the relationship between Islam and Christianity, and Islam and the West, are often overwhelming and have considered each other as strangers and invaders. And in the near future, two civilizations that can conflict with each other are Islamic civilization and Christian or Western civilization (Mansour, 2001: 45).

Looking at the developments in the Middle East, especially after the "Islamic awakening" and the crises in Syria and Iraq can be said that the theory of the clash of civilizations, the context of explaining international relations and civilizational conflicts between the West and Islam has been made noticeably. As acknowledged by most experts and researchers in the field of international politics, Syria is a point to begin a new phase of conflict between the two Western and Islamic civilizations and this country also the focus of the formation of regional and even new international orders. In this crisis, the actors belonging to different civilizations are involved; on one hand, are involved the government of Bashar al-Assad, terrorist groups like Jabhat al-Nusra, ISIL and Ahrar al-Sham and on other hand, the United States and its European allies, Saudi Arabia and some Persian Gulf States, and Iran and the axis of resistance, as well as Russia and China.

Accordingly, given the presence of various cultures and religions, it seems that this will make the Syrian crisis a prelude to a renewed clash of civilizations. So, the present research seeks to answer these questions: What are the basic propositions of the theory of the clash of civilizations and how is it represented in the Syrian crisis? Since according to Samuel Huntington, the foundation of civilizations, religious and cultural backgrounds, and cultural and religious identities are the main source of the clash of civilizations; Therefore, the war on terrorism, the Syrian crisis, the emergence of ISIL and the presence of the US military and international interventions, the competition of regional and trans-national powers, is express the clash of civilizations.

\section{Discussion}

The theory of "clash of civilizations" was born in 1993, with the publication of an article in the "Foreign Policy" journal by Samuel Huntington. In fact, this theory was introduced with the aim of explaining the new world order in the post-Cold War era. During the Cold War, disputes and conflicts among societies were assessed on the basis of ideological rivalries between the East and West blocs; But after the end of the bipolar system and the emergence of a United States-led monopoly system, developments in the international system arose from ethnic and religious conflicts and tensions in different parts of the world. In this regard, the fundamental principle of Huntington's theory was based on the distinction between different nations, not political and economic, but based on cultural distinctions. On the other hand, new patterns of conflict between societies occur in the field of cultural affairs, and not merely limited to competitive patterns in the political and economic arena. In this context, Huntington noted: The main source of conflict in this new world is not ideological or often economic. The widespread division of humanity and the resources 
governing the war will be cultural. The nation-states will remain the main and powerful actors in the international system, but major conflicts occur among international actors and different groups of civilizations and the clash of civilizations will dominate global politics (See: Huntington, 1993).

Thus, the main components of Huntington's view can be summarized as follows:

1. New identities, such as Islamic fundamentalism, have a cultural nature derived from the formation of "consciousness of civilization" and this exacerbates the irreconcilable contradictions of civilizations.

2. People are discovering a new identity, but at the same time, their own, in which the ideologicalcivilizational struggles play a pivotal role.

3. The two Islamic and Confucian cultures are the cultures that challenge the civilization of the West and can see the tensions and conflicts about their civilization lines with the West, the spheres, or the fault lines of tension and conflict.

4. The existence of a similar and almost complete system of values and beliefs within each civilization, enhance their equipped feature and cannot see serious conflicts between countries belonging to a civilization.

5. The capacity of Islam as an ideological system in determining political behaviors and actions for the establishment of organizational and identity structures (Ashraf Nazari and Ghanbari, 2013: 137).

In the same regard, Huntington classifies the world into the eight main civilizations that, in order to better explain the research issue, in the map of the distribution of civilizations all over the world from his perspective, after the divisions of civilization are observed:

Thus, the theory of the clash of civilizations is based on two principles: First, in the next world, the main conflict between Muslims and non-Muslims [the confrontation between the civilization of Islam and the West] and second, the United States does not engage in conflicts in other civilizations, but rather to contain these conflicts through negotiation (or deal). US attack on the Taliban regime, al-Qaeda, bin Laden, ISIL and its involvement in Afghanistan and Iraq, as well as the Middle East crises (Hakimipur, 2014: 4), this angle can be explained.

According to Huntington, there are five main reasons for the inevitability of the encounter between Islamic and Western civilizations:

- The Muslim population is growing while producing a large number of unemployed and unhappy youth. This unemployment will be a factor in putting pressure on neighboring states and ultimately to migrate to the West.

- The resurrection of Muslims will give them renewed confidence; it is because of its distinctive features and their civilization values compared to Western civilization. 
- The simultaneous effort of the West to globalize its values and laws and maintain military-economic supremacy and intervention in the disputes of the Muslim world has created grave discontent among Muslims.

- The collapse of the Soviet Union destroyed the common enemy of Islam and the West and allowed them to imagine each other as a threat to each other.

- Increasing the relationship between Muslims and the West simultaneously threatens a new sense of identity and its difference with another (Vosoughi, Safari: 2014: 106).

Therefore, Huntington believes that the confrontation between civilizations is the dominant global policy and the last stage in the evolution of the conflicts of our time. According to him, the propositions that will lead to this confrontation are: The difference between civilizations is fundamental; Civilization's selfawareness is on the rise; Religious revival, a means to fill the vacuum identity is growing; Dual behavior of the West has raised the self-awareness of civilization (others); Characteristics and cultural differences, are immutable; Economic regionalism and the role of cultural commonalities are growing; Lines of fault between today's civilizations; Replaced the political and ideological frontiers of the Cold War era and these lines are the sparks of a crisis and bleeding and The 1400-year-old hostility of the West and Islam is on the rise and relations between these two civilizations are pregnant with bloody incidents (Mohammadi, 2008: 46-45) that a prominent example emerged in recent years in the Syrian crisis (2011-present). In the following, he will explain the theory of the clash of civilizations in the Syrian conflicts. But before addressing it, it is necessary to examine this theory in the Middle East and then examine the developments in Syria.

The Middle East region, due to its geopolitical importance over the past years has always been the focus of attention of foreign governments and colonial powers. Today, this area because of its strategic and its geopolitical location and political situation, an important element influencing on international equations is considered (Jomee' $i, 2009: 7)$. This area has always been a sphere of influence and conflicts of regional and trans-regional powers and their presence and influence in this area is one of the most important factors, in determining the position of regional and global powers. Therefore, the various factors that make the Middle East more important, it can be called one of the unique sources of energy and the geopolitical and geo-economical privileges of this region. On the other hand, the continuation of the Arab-Israeli conflict, the crisis in Iraq, Lebanon and Syria, Arms race, Proliferation of Weapons of Mass Destruction, increasing ethnic and religious gaps, increasing terrorist activity are one of the most important threats in this region. In addition to energy, the issue of security and supremacy of the Zionist regime in the region is also a major contributor to insecurity and instability (Akhbari et al., 2011: 95).

In addition, the Middle East has unique features that can be found in lesser regions of the world, in this area, there are six different breeds living side by side. This region is the birthplace of three different religions, Islam, Christianity, and Judaism. The traditional culture in the Middle East is basically founded on the principles of the religion of Islam. Another important element that has added importance to the Middle East and has made it an important cultural hub, there are various hometowns including Islamic civilization in this region that is considered as a rival civilization in Western civilization, especially in the liberal Christian civilization ruling Europe and America. Many scholars in Western civilization, including Huntington, will consider the future of the relationship between these two civilizations in the future of the world (Moinaldini, 2007: 63). 
One of the hallmarks of the clash of civilizations in the Middle East is the regional and trans-regional powers' competitions to preserve their domination and influence in the region. Because, in these conflicts, any power that can overcome other powers is, in fact, the dominant power in the Middle East. Since the competition of powers in the form of two western and Islamic civilizations can be interpreted, therefore, according to Huntington's idea, every civilization that wins in this conflict will be the dominant civilization in the region. For this reason, given the ethnic and religious pluralism of the region, competition within civilization and Huntington's great emphasis on Islamic civilization, establishing a coalition of countries in line with Western interests against the anti-Western countries will be inevitable. Therefore, pushing for the axis of resistance (Iran, Syria, Iraq, Hezbollah, and Hamas) and increasing the arms race and turning Persian Gulf countries into the largest strategic market in the West within the framework of the clash of civilizations (Islam and the West) can be interpreted.

According to international experts, in recent years (especially after the Islamic awakening), the Middle East region (West Asia) has proven prominently Samuel Huntington's theory of the clash of civilizations. In fact, thoughts and opinions of Huntington have maintained their status despite criticism and flaws. As examples of continuing the frequent wars against terrorism (Takfiri and Salafi currents), The Syrian crisis and the emergence of ISIL, the relatively permanent military presence of the United States in the Middle East, Interventions and competitions of regional and trans-regional powers in this region, and so on, suggests to the war between civilizations. It is noteworthy that the Middle East, due to it's the geopolitical, geostrategic, and geo-cultural situation, is very important in the international system. Without a doubt, the presence of trans-regional powers such as the United States, the European Union, Russia, and China on the one hand and regional powers such as Iran, Saudi Arabia, Turkey, on the other hand, endorses the clash of civilizations and the confrontation between the West and Islam. This is particularly apparent in the Syrian crisis.

In this regard, Huntington, like other contemporary analysts and scholars, the potential confrontation between Western and Islamic civilization is accepted as a definitive principle in the formation of a new international order. Hence, "Stephen Eric Bronner," wrote in his book "Twentieth Century Political Theory": The multi-hundred-year military confrontation between the West and Islam is unlikely to be reduced. This can be considered more dangerous. In the Persian Gulf War, some Arabs are proud that Saddam Hussein has raided Israel and stands against the West. Also, many Arabs, from the sense of humiliation and the suffering of the Western military presence in the Persian Gulf and The obvious weakness of [the Arab countries], they suffer greatly in determining their fate. [...] Developments have taken place in some centers of Arab political systems. The main winners of these developments were Islamic movements. Briefly, in the Arab world, Western democracy strengthens anti-Western forces. This issue may be a transient phenomenon, but it certainly complicates relations between the Islamic countries and the West (See: Bronner, 2005: 445). Obviously, the components and principles of Huntington's theory were reflected as an official doctrine not only at the regional level but also at the international level.

Therefore, considering Asia and the Middle East as an integral civilization is a fallacy; because it hides the fact that many conflicts in these areas have occurred within civilizations. It is no coincidence that Saudi Arabia and Egypt are different from the behavior of Iran and Iraq and securing your interests in engagement with or controversy with the United States. Thus, if the West forms a unit block, as Huntington seems to believe; in the face of "Islamic threat" will unite. But as the collapse of the Persian Gulf War Coalition showed, the West believed that how can respond to the invasions of Saddam Hussein (See: 
Heilbrunn, 1998). On the other hand, following Huntington's theory, when the wars in Afghanistan and Iraq began in 2001 and 2003, these events, have been placed to the Western powers against many of the state and non-state actors (Hezbollah and Hamas) of the Islamic world. Because it coincided with the weakening of the West's civilization in the Middle East conflicts; while US performance (as a symbol of Western civilization) in the World War on Terrorism has increased over the past two decades, but there is no doubt that the conflicts of Western-Islamic civilization play an important role in shaping international developments after the Islamic Awakening in the Middle East and North Africa. In this sense, the role of regional and trans-regional actors in the Middle East conflicts from Palestine, Lebanon, Syria, Afghanistan, Iraq to the Horn of Africa: Egypt and Tunisia, Libya and Sudan appear to be the clash of Islamic and Western civilizations.

Over the past years, especially after the Syrian crisis, the role of radical and terrorist groups, including ISIL, has increased dramatically, and on an ever-increasing scale, its importance in the field of international relations is increasing. ISIL is currently one of the most powerful terrorist groups ${ }^{1}$ in the world and is even more violent in using violent methods of al-Qaeda. Moreover, as Huntington claims; new actors of international conflicts are no longer governments, but also are civilizations. He defines this concept as "the main human cultural group" that are known both with objective elements (language, history, religion, adverbs, and institutions) and through the mental elements of individuals. Accordingly, ISIL is an image of this new concept in the international arena.

In the international system, according to Samuel Huntington's view, long conflicts will occur not only between different states but also between different civilizations. In fact, political ideologies or institutions can change, while civilizations based on religion cannot change. ISIL shows this concept by its definition of religious beliefs and cultural values. They also fight with everyone who does not match their cultural qualities. ISIL in this era shows that clashes between non-state actors occur from different civilizations, and national governments are no longer the main actors. Yet, with the definition of Huntington from civilization, this is also challenged. In fact, although ISIL challenges non-Islamic civilizations, especially the West, but it also fights with institutions (individuals) within Islamic civilization. As a result, ISIL shows the clash of civilizations (See: Gray, 2014).

Huntington's theory based on the clash of civilizations, In the Syrian crisis in 2011, it was clearly seen that this is being discussed further. Huntington believes that the process of globalization, which has led to the disappearance of political boundaries, On the one hand, it has increased among nations belonging to different civilizations and, on the other hand, has increased the distance between civilizations (Zarean, 2016: 74). The beginning of the crisis in Syria and the transformation of the crisis from the security situation to the military, The Syrian political system was incapacitated to control a large part of the country, and in this situation, an area was created to ISIL's influence and was provided their more expand (Zarean, 2016: 79). In this regard, the representatives of Western civilizations led by the United States of America have fully exploited the situation and tried to infiltrate and maximize their own interests from the crisis. Thus, despite apparent opposition to the issue of terrorism and extremism in the Middle East, but in practice, from ISIL and other extremist groups in order to confront the axis of resistance (Islamic civilization), Avoiding the influence of Russia and China in this region (Slavic civilization and Chinese civilization) provides arms and

\footnotetext{
${ }^{1}$ It is worth noting that this group (ISIL) collapsed after the release of Mosul in Iraq and al-Raqqa in Syria.
} 
financial support. In this context, Huntington wrote in an article: Islam and the West are in conflict with each other. Islam threatens the West in three directions: politics, civilization, and demographics. In his view, the relationship between Western civilization and Islamic civilization has always been based on a pattern of military conflict and will be. In this regard, Muslims are an invading force, and the borders of Islam are the bloody borders that created with the war (Alipour et al., 2016: 210).

Obviously, Huntington's concern is the Islamic civilization. Also, the main concern of the West is to increase the strength of the Islamist movements, strengthen the position of the axis of resistance (Syria and Iran, Hezbollah and Hamas) and therefore, opposition to Islamic civilization is on the agenda of representatives of Western civilization (especially the United States of America). For example, the situation prevailing over ISIL's hometown, whether inside the country that was the balance between the dissidents and supporters of Bashar El-Assad, whether inside the region that the classification of countries and rival regional powers against each other has been ongoing and whether inside the world that witnessed hostile and conflicting rivalries of the world powers in relation to ISIL, prepared for growth and development influence of the ISIL (Alipour et al., 1393: 211). Thus, Syria was the battleground for the Islamic, Western, Slavic, and Chinese civilizations, or in the context of the struggle between regional and trans-regional powers. Accordingly, they are benefited from the opportunity of ISIL influence and trying to erode the internal conflicts in Syria. This can be interpreted within the framework of the theory of the clash of civilizations on the victorious civilization, dominant in the most strategic region of the world.

In addition to the geopolitical factor, the conflict between the interests of regional and trans-regional powers in Syria has led to rivalry between them. Since each of these powers has certain interests and specific strategies in this country and conceptually, they have a unique civilization; therefore, in the Syrian crisis, we are facing to civilizational conflicts or according to Huntington's "clash of civilizations." In fact, Syria, along with Iran, is one of the components and elements of the axis of resistance and in this way, Iran supporting Palestinian jihadist groups, especially Hamas and the Palestinian Islamic Jihad, as well as Hezbollah against Israel. Thus, the formation of Syria's internal protests in March 2011, provided the field of foreign intervention and turned this country into a scene of competition and the clash of civilizations known in Huntington's theory. Meanwhile, given the reasons for the presence of regional and trans-regional powers in the Syrian crisis, on the one hand, can clearly see the main actors of this crisis from the Western, Russian (Slavic), Islamic, and Chinese civilizations that are in competition with each other. So that Western civilization in confrontation with Chinese and Islamic civilization and Chinese civilization in the face of Western, Islamic and Russian civilization, Islamic civilization is in confrontation with the West and a mild encounter with Chinese and also Russian civilization is in conflict with the Western civilization.

On the other hand, we are witnessing civilization rivalries between the three regional powers of Iran, Turkey, and Saudi Arabia, which requires another study, but here it is just mentioned in order to better explain this issue. In fact, Huntington's emphasis on the theory of the clash of civilizations on Islamic civilization, for example, the United States of America, as the main representative of Western civilization, seeking to weaken the axis of resistance and to this end, welcomes the continuation of the Middle East political and security crises. The axis of resistance consists of an alliance of states and non-state actors in the Middle East that seeks to combat the interests of Western countries, including the United States and Israel; increasing the presence of resistance forces, including Hezbollah, is the main concern of the United States (Vosoughi, Safari, 2016: 115). In fact, the US strategy toward the Middle East (which is the heart of Islamic civilization) is based on the support of traditional dictators, and based on three distinct goals in this 
area, namely maintaining the security of oil transit, the lack of emergence of new power, and, above all, maintaining the security of the Israel. On this basis, establishing good communication with totalitarian regimes, such as Saudi Arabia, Egypt, and the Gulf monarchies has been on the US agenda. On the other hand, the regional dictatorial regimes have played an important role in preserving the "Status Quo" and the unilateral world order.

In the theory of the clash of civilizations, Huntington points out that there is a good link between Islamic civilizations and Confucianism in China, which can challenge the influence and power of Western civilization. China benefits from good relations with the Muslim world. China has good business relations with Islamic countries including Iran, Pakistan, Sudan, and Syria. However, there are also disagreements between them, and the concern of Muslims [of the Islamic civilization] is that of the encounter of China with the Muslim population of the Uighurs region of China [Xinjiang] (See: Alkan, 2014: 60). Despite these concerns, it must be admitted that China, which in turn represents the Chinese civilization (Confucianism) and Russia (which was neglected in Huntington's theory) as a representative of Slavic civilization, As the civilian conflict entering into the Syrian crisis, it has tried to expand its sphere of influence in West Asia (Middle East) and By communicating closely with countries such as Iran, defines its regional policies in opposition to the interests of the countries representing Western civilization (US and European) and Somehow they have created clash of civilizations. In other words, China, Russia, and Iran, each representing a great international civilization at the international level, by forming a coalition in the Syrian crisis, the interests of the United States and Europe have been overshadowed by the representatives of Western civilization and eventually created a clash of civilization.

Also, Huntington puts forward three major civilizations in the clash of civilizations: West, Islam, and China. The point he neglects is the importance of the orthodox or Russian civilization. Perhaps the collapse of a longtime US rival during the plan of this theory, it has been more than that that he remembers the importance of civilization, such as Russia (namely Huntington assumed that Slavic civilization had collapsed) and putting them alongside Chinese civilization at the forefront of the civilization battle. The two countries of China and Russia, each representing a great civilization in the war of civilizations, in recent years, having entered geopolitical and regional games, and also by trying to expand its sphere of influence in Asia and the Middle East, and by closely co-operation with countries such as Iran and Syria, it has taken regional policies in opposition to the interests of Western civilization especially the United States, and Interpret the perspective of the region and even the world as an East-West and several civilizations. The strong support of China and Russia (and especially Russia) from Syria in the recent crisis, is indicative of the fact that Russia is in no way compromised over its geopolitical interests in the region and This, has put Western civilization in serious problems. What can be seen today from the involvement of civilizational identities in geopolitical zones, that is, the time for the superiority of Western civilization has come to an end and the three oriental civilizations have come into conflict with Western civilization in a coordinated approach with the unity of the vast front came to battle with the West. These three civilizations (Islamic with the representation of Iran, Orthodox with the Russian representation, and Confucius with the representation of China) are now the rivals of the West of the American-centered civilization and Western civilization is confronting these three civilizations on separate fronts, and seeks to prevent the spread of strategic depth and their sphere of influence in the Middle East and Syria. 


\section{Conclusion}

There are three factors in the Middle East strategic area, being on the eastern coast of the Mediterranean Sea and neighboring Occupied Palestine, Lebanon, Turkey, and Iraq, clearly illustrates the geopolitical importance of Syria in regional and global relations. The Syrian conflict has become a global issue due to axial geopolitics. The conflict between the interests of regional and trans-regional powers in Syria has led to rivalry between them. Since each of these powers has certain interests and strategies in this country and therefore, in the Syrian crisis, we encounter civilizational conflicts or according to Huntington's "clash of civilizations." Syria and Iran constitute one of the components and elements of the axis of resistance, and in this way supporting the Palestinian jihadi groups, especially Hamas and the Palestine Islamic Jihad, and also Hezbollah against Israel. Thus, the formation of Syria's internal protests in March 2011, provides Foreign Intervention fields and transformed this country into a scene of competition and the clash of civilizations known in Huntington's theory. Due to the issues presented in this study, can be concluded that, in accordance with the theory of the clash of civilizations, In the future, the main conflict is between Muslims and non-Muslims, or the clash of civilization between Islam and the West. Generally, civilizational conflicts in the Middle East and the Syrian crisis became both practical and theoretical. In theory aspect, it can be said that the plan of theories such as the "end of history" by Francis Fukuyama and the "clash of civilizations" by Samuel Huntington inevitably clashes with civilizations. Because the main concern of the two thinkers is the strengthening of the position of Islamic civilization in the coming years. On the other hand, the various actions that Western countries have taken to counter the growth and development of Islamic civilization, especially in the Middle East due to its strategic location, including the formation of ISIL, shows that in recent years, especially after the start of the Syrian crisis, the conflict has widened between the two Western and Islamic civilizations. According to this, should be noted Since the according to Samuel Huntington, the foundation of civilizations, religious and cultural backgrounds, and cultural and religious identities are the main source of the clash of civilizations; Therefore, the war on terrorism, the Syrian crisis, the emergence of ISIL and the presence of the US military and international interventions, the competition of regional and trans-national powers, is express the clash of civilizations.

\section{References}

Alkan, A, (2014), is there really a Clash of Civilizations? The Nature of Present World Order after Huntington and the Explanations of Clash within Civilization Orbits, Asian Journal of Science and Humanities, Vol, 3. No. 4.

Bronner Stephen Eric (2005), Twentieth Century Political Theory, Psychology Press.

Dasheiri Mohammad Reza and Golestan Moslem (2016), the Great Powers' Major Styles in Managing the Syrian International Crisis in the Monopolar System, International Political Research, 25.

Eugene Chausovsky (2016), Why Civilizations Really Clash, Available at https://worldview.stratfor.com/article/why-civilizations-really-clash (2018/01/29).

Gray, John (2014), Isis: an apocalyptic cult carving a place in the modern world, The Guardian, 26th August 2014 
Heilbrunn Jacob (1998), the Clash of the Samuel Huntington's, the American prospect, JULY-AUGUST 1998, Available at http://prospect.org/article/clash-samuel-huntingtons (2018/01/29).

Huntington, Samuel P. (1993), the Clash of Civilizations? Foreign Affairs, 72, no. 3 (1993).

Huntington, Samuel P. (1996), the Clash of Civilizations and the Remaking of World Order. New York, NY: Simon and Schuster, 1996.

Mansoor, Ayub (2001), The Clash of Civilizations: The Reconstruction of the New World Order, translated by Saleh Vasely, Political Science Association of Shiraz University, 1 (3).

Naderi Ahmad (2016), the geopolitical state-centered, to geo-culture-centered civilizations, the Middle East, the area of clash of civilizations, Soft power studies, 4 (10).

Soleimani Fatemeh (2014), China's new military strategy: regional and international dimensions and consequences, Political Studies Office of Majlis Research Center, July 2014, No. 14322.

Vosoughi Saeed; Safari Asgar (2015) The role of the United States in extremists in the Middle East with an emphasis on Iraq and Syria, Strategic Policy Studies, 5 (17).

Zarean Ahmad (2016), The Basics of the emergence and expansion of ISIL in the security environment of West Asia, Afagh Security, 7 (27).

\section{Copyrights}

Copyright for this article is retained by the author(s), with first publication rights granted to the journal.

This is an open-access article distributed under the terms and conditions of the Creative Commons Attribution license (http://creativecommons.org/licenses/by/4.0/). 